\title{
Snake venom, bee venom and their components exert an anti-cancer effect by triggering apoptosis and cell cycle arrest in prostate cancer
}

\author{
Original \\ Mona I. Elrefay', Abir A. Elfiky ${ }^{1}$, Rabab H. Sayed ${ }^{2}$ and Hala F. Zaki ${ }^{2}$ \\ Article \\ ${ }^{1}$ African network for development and innovation center of excellence in antivenom research, \\ VACSERA, Cairo, Egypt. \\ ${ }^{2}$ Department of Pharmacology and Toxicology, Faculty of Pharmacy, Cairo University, Cairo, \\ Egypt.
}

\begin{abstract}
Background: Snake venom (SV), bee venom (BV) and their bioactive components are unique sources for cancer therapy development. The present study evaluated the anticancer potential of SV, BV and their major components (SV phospholipase A2 (svPLA2), melittin (MEL) and BV phospholipase A2 (bvPLA2)) against human prostate adenocarcinoma (PC3).

Materials and methods: Cytotoxicity was conducted using MTT biochemical assay. Genotoxicity was performed using real tine PCR for detection of pro-apoptotic and anti-apoptotic genes as well as the biomarker genes for prostate cancer. Cell arrest accumulation was highlighted using flowcytometry.

Results: MTT assay showed that treatment with SV and BV and their major components resulted in cellular morphological changes and significant cytotoxic effects in PC3. Furthermore, our results indicate that the svPLA2 gives much lower cytotoxic effect than the crude SV in PC3 cells in the highest tested concentration of $100 \mu \mathrm{g} / \mathrm{ml}$. On the other hand, the major components of BV (bvPLA2 and MEL) showed more potent efficacy on PC3 cells than the crude BV. Interestingly, we showed that SV, svPLA2, BV, bvPLA2 and MEL suppressed the mRNA expression of the anti-apoptotic protein Bcl2, while increased the mRNA expression of the pro-apoptotic protein Bax. Moreover, they decreased the overexpressed prostate tumor marker genes. The cell cycle analysis showed that SV and svPLA2 arrested the cell cycle at G0/G1 phase, while BV, bvPLA2 and MEL arrested cell cycle at G2/M phase.

Conclusion: Our work demonstrated that SV, BV and their major components inhibit prostate cancer possibly via triggering apoptosis and cell cycle arrest.
\end{abstract}

Received: 07 September, 2019, Accepted: 21 October, 2019.

Key Words: Apoptosis, bee venom, cell cycle, prostate cancer, snake venom.

Corresponding Author: Rabab Hamed Sayed, Faculty of Pharmacy, Kasr El Aini St., Cairo University, Cairo, Egypt, Post Office Box 11562, Tel.: +201001414473, Fax:+2023635140, E-mail: rabab.sayed@pharma.cu.edu.eg.

Bulletin of Faculty of Pharmacy, Cairo University, ISSN: 1110-0931, Vol. 57, No. 2

\section{INTRODUCTION}

Prostate cancer is the most common cancer, as well as the second leading cause of cancer-associated mortality in men worldwide ${ }^{[1]}$. Although the use of chemotherapeutics in cancer therapy remains the predominant option for clinical control, the development of resistance and associated severe side effects are common and critical problems ${ }^{[2]}$. Therefore, there is an urgent need to develop novel safe and effective therapeutic agents to fight this disease. Recently, several dieary compounds have been at the forefront research of new therapies against prostate cancer.

Apoptosis is the process of programmed cell death which has a critical role in anti-cancer effects of chemotherapeutics $^{[3]}$. Evidence shows that the failure of cells to undergo apoptosis has been associated with development of resistance to cancer therapy ${ }^{[4,5]}$. Therefore, therapeutic agents that target the apoptotic pathway, including pro-apoptotic proteins activators or inhibitors of anti-apoptotic proteins, may lead to the regression of cancer cells and an improved prognosis of refractory disease $\mathrm{e}^{[6]}$.

The biodiversity of venoms made them a unique source from which new therapeutic agents may be developed. Bee venom (BV) contains a variety of different peptides including melittin (MEL), phospholipase A2 (bvPLA2), apamin, adolapin and mast cell-degranulating peptide ${ }^{[7]}$. $\mathrm{BV}$ has been used as a traditional medicine to treat a variety of conditions, such as back pain, rheumatism, cancerous tumors, and skin diseases by its antibacterial, antiviral, and anti-inflammatory effects ${ }^{[8]}$. Several studies have revealed that BV and its components; MEL and bvPLA2, have anti-proliferative effect on various cancer cells such as prostate ${ }^{[9]}$, ovarian ${ }^{[10]}$, liver ${ }^{[11]}$, cervical ${ }^{[12]}$ and renal ${ }^{[13]}$ cancer cells through induction of apoptosis. 
Snake venom (SV) is a complex mixture of enzymes, peptides, carbohydrates, minerals and proteins of low molecular mass with specific chemical and biological activities $^{[14]}$. Components of SVs can be used in the treatment of cancer, arthritis, thrombosis, multiple sclerosis, pain, neuromuscular disorders, blood and cardiovascular disorders, infections and inflammatory diseases ${ }^{[15]}$. SV components including phospholipase A2 (svPLA2) basically inhibit cell proliferation and promote cell death by increasing or decreasing the expression of proteins that control cell cycle, inducing cancer cell apoptosis thereby controlling tumor size and cytotoxicity ${ }^{[16]}$. However, the comparison of the anticancer activities of crude SV, BV and their major components in prostate cancer cell lines has not been reported yet. Therefore, the aim of the present study was to evaluate the anticancer activities of the crude SV, BV and their major components (svPLA2, melittin and bvPLA2) against human prostate adenocarcinoma (PC3) and to explore the effects of these tested compounds on the prostate adenocarcinoma biomarker genes; namely prostate-specific antigen (PSA) and prostate cancer antigen 3 (PCA3), and the expression levels of the apoptotic genes as well as on the cell cycle of the tested tumor cells.

\section{MATERIALS AND METHODS}

\section{Chemicals}

RPMI 1640 medium, L-glutamine, fetal bovine serum (FBS), dimethyl sulfoxide (DMSO) and other cell culture materials were all purchased from Fisher Scientific Cell Culture (Houston, TX, USA). Fine chemicals and reagents, unless otherwise specified, were obtained from SigmaAldrich Chemical Co. (St. Louis, MO, USA).

\section{Culture cells and venoms}

Human prostate adenocarcinoma cells; PC3 cells (ATCC number: HTB-22), were obtained from The Egyptian Holding Company for Production of Vaccines and Sera and Drugs (VACSERA)-Egypt. PC3 cells were cultured in RPMI medium supplemented with $10 \%$ FBS, $1 \%$ penicillin/streptomycin and $2 \mathrm{mM}$ L-glutamine. The cell cultures were maintained at $37{ }^{\circ} \mathrm{C}$ and $95 \%$ humidified atmosphere with $5 \% \mathrm{CO}_{2}$. SV Naja haje (Egyptian Cobra) and BV from Apis mellifera (honey bee) lyophilized powder were purchased from VACSERA. SvPLA2 from Naja haje (Egyptian Cobra), bvPLA2 and MEL from Apis mellifera (honey bee) lyophilized powder were purchased from Sigma-Aldrich Chemical Co. (St. Louis, MO, USA).

\section{Cytotoxicity assay}

Cytotoxicitywasevaluatedusing3-(4,5-dimethylthiazol2-yl)-2,5-diphenyltetrazolium bromide (MTT) assay. The cells were plated at concentration of $2 \times 105$ cells $/ \mathrm{ml}$ in the 96- well tissue culture plate with $100 \mu \mathrm{L}$ of RPMI medium. The cells were treated with different concentrations $(0.01,0.1,1,10$ and $100 \mu \mathrm{g} / \mathrm{ml})$ of $\mathrm{SV}, \mathrm{BV}$, svPLA2, bvPLA2, MEL and doxorubicin (DOX) for $24 \mathrm{~h}$ at $37^{\circ} \mathrm{C}$ to determine their IC50s (the concentration of the drug required to produce $50 \%$ inhibition of cell growth). For each sample, three wells were used for each concentration. After each incubation time, $50 \mu \mathrm{L}$ MTT salt $(5 \mathrm{mg} /$ ml) were added to each well in the dark condition and incubation continued for $4 \mathrm{~h}$. Then, the supernatants were discarded and the formazan precipitates were solubilized by addition of DMSO $(50 \mu l)$ to each well. The optical densities (ODs) were measured using ELISA plate reader (ELx-800, Biotek, USA) at wavelength $570 \mathrm{~nm}$. Cell viability percent was calculated as (OD of treated cells / $\mathrm{OD}$ of untreated cells) $\times 100$. The $\mathrm{IC}_{50}$ value of each venom was calculated using MasterPlex QT Quantitation Software (MiraiBio, Alameda, CA). Morphological changes of treated PC3 cells with each venom were examined $24 \mathrm{~h}$ post treatment using an inverted phase contrast microscope and finally morphological events were compared with untreated cells.

\section{Real-time PCR analysis}

Total RNA was extracted from control and treated PC3 cells using the GeneJET RNA purification kit (Fermantus, UK) and the purity of the obtained RNA was confirmed spectrophotometrically by OD $260 / 280 \mathrm{~nm}$. First-strand cDNA was synthesized with $1 \mu \mathrm{g}$ of total RNA using an RT-PCR kit (\#K1621, Fermentas, Waltham, MA, USA) in accordance with the manufacturer's instructions. To access the mRNA expression of Bax, Bcl-2, PSA and PCA3 genes, RT-PCR was performed using QauntiTect SYBR Green PCR kits (Qiagen, Germany). The primer sequences used are described in Table 1. Real-time PCR mixture consisted of $12.5 \mu \mathrm{L} 2 \mathrm{x}$ SYBR Green PCR Master Mix, $1 \mu$ Lof each primer $(10 \mathrm{pmol} / \mu \mathrm{L}), 2 \mu \mathrm{L} \mathrm{cDNA}$ and $8.5 \mu \mathrm{L}$ Rnase-free water in a total volume of $25 \mu \mathrm{L}$. The thermal cycler protocol consisted of an initial enzyme activation at of $95^{\circ} \mathrm{C}$ for $15 \mathrm{~min}$, followed by 40 cycles of denaturation at $94^{\circ} \mathrm{C}$ for $15 \mathrm{sec}$, annealing at $60^{\circ} \mathrm{C}$ for $30 \mathrm{sec}$ and elongation at $72^{\circ} \mathrm{C}$ for $30 \mathrm{sec}$. Melting curves were done after real-time PCR to validate the specific amplification of single products of interest. The relative expression of the target gene was obtained using the comparative $2^{-\Delta \Delta \mathrm{CT}[17]}$. All values were normalized to that of $\beta$-actin and presented as fold-change.

Table 1: The primer sequences used for real-time polymerase chain reaction:

\begin{tabular}{ll}
\hline Gene & \multicolumn{1}{c}{ Primer sequences } \\
\hline \multirow{2}{*}{ Bax } & F: 5'-ATGGACGGGTCCGGGGAGCA-3' \\
& R: 5'-CCCAGTTGAAGTTGCCGTCA-3' \\
\multirow{2}{*}{ Bcl-2 } & F: 5'-GTGAACTGGGGGAGGATGT-3 \\
& R: 5'-GGAGAAATCAAACAGAGGCC-3' \\
PSA & F: 5'-GACCACCTGCTACGCCTCA-3' \\
& R: 5'-GGAGGTCCACACTGAAGTTTC-3' \\
PCA3 & F: 5'-AAAGGAAGCACAGAGATCCCTG -3' \\
& R: 5'-GGGCGAGGCTCATCGAT-3' \\
GAPDH & F: 5'-CAAGGTCATCCATGACAACTTTG-3' \\
& R: 5'-GTCCACCACCCTGTTGCTGTA G-3' \\
\hline
\end{tabular}




\section{Cell cycle analysis using flow cytometry}

PC 3 cells precultured in $25 \mathrm{~cm}^{2}$ cell culture flasks were treated with an $\mathrm{IC}_{50}$ of test venom dissolved in RPMI-1640 medium, for $24 \mathrm{~h}$. Only adherent cells were harvested, washed with cold PBS, and fixed gently with $70 \%$ ethanol. After ensuring fixation, the cells maintained at temperature of $4^{\circ} \mathrm{C}$ overnight and then incubated with PBS containing $40 \mu \mathrm{g} / \mathrm{ml} \mathrm{PI}, 0.1 \mathrm{mg} / \mathrm{ml}$ RNase and $0.1 \%$ Triton X-100 in a dark room at $37^{\circ} \mathrm{C}$ for $30 \mathrm{~min}$. Cell cycle analysis was measured by a flow cytometer (Becton-Dickinson, San Jose, CA, USA) equipped with an argon ion laser at a wavelength of $488 \mathrm{~nm}$.

\section{Statistical analysis}

The data are presented as mean $\pm \mathrm{SD}$ from three different experiments and comparisons between means were carried out using one way analysis of variance (ANOVA) followed by Tukey-Kramer multiple comparisons test. The level of significance was fixed at $P<0.05$ for all statistical tests using SPSS Program.

\section{RESULTS}

The cytotoxicity of $S V$, svPLA2, BV, bvPLA2, MEL and DOX on PC3 cells

To evaluate the effects of SV, svPLA2, BV, bvPLA2, MEL and DOX on the viability of PC3 cells, MTT assay was carried out. PC3 cells were treated with serial concentrations $(0.01,0.1,1,10$ and $100 \mu \mathrm{g} / \mathrm{ml})$ of the test products for 24 hours. As shown in (Figure 1), PC3 cell viability was significantly decreased in a dose-dependent manner by all treatments to $2.08 \%, 15.59 \%, 1.82 \%$, $1.63 \%, 1.17 \%$, and $17.62 \%$ at $100 \mu \mathrm{g} / \mathrm{ml} \mathrm{SV}$, svPLA2, $\mathrm{BV}$, bvPLA2, MEL and DOX, respectively. The $\mathrm{IC}_{50}$ values for SV, svPLA2, BV, bvPLA2, MEL and DOX were 0.06, $0.84,0.09,0.15,0.11$, and $0.42 \mu \mathrm{g} / \mathrm{ml}$, respectively. The tested venoms and their components were almost efficient as DOX, a currently used anti-cancer drug.

Regarding the morphological changes, it was noticed that the control cells exhibited polygonal shape with distinct boundaries and homogenous or slightly granulated cellular contents. On the other hand, cells incubated with test products at $\mathrm{IC}_{50}$ concentration showed a number of morphological abnormalities after $24 \mathrm{~h}$ of treatment. Treated cells started to show gradual cell shrinkage, cell rounding, detaching from the surface of tissue culture flasks and floating in the tissue culture medium, and finally they showed obvious cell swelling and rupture (Figure 2).
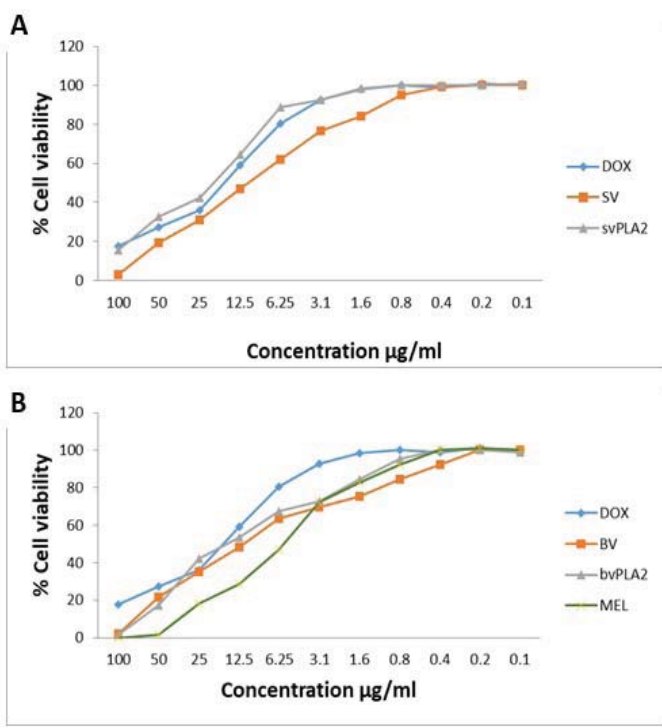

Figure 1: Drug The cytotoxicity of (A) DOX, SV and sv-PLA2 and (B) DOX, BV, bvPLA2 and MEL on PC3 cells. Cells were seeded in 96-well tissue culture plates and treated after $24 \mathrm{~h}$ with different concentrations of SV, BV, svPLA2, bvPLA2, MEL and DOX. Percent of cell viability was calculated in relation to the untreated control using MTT colorimetric assay method.
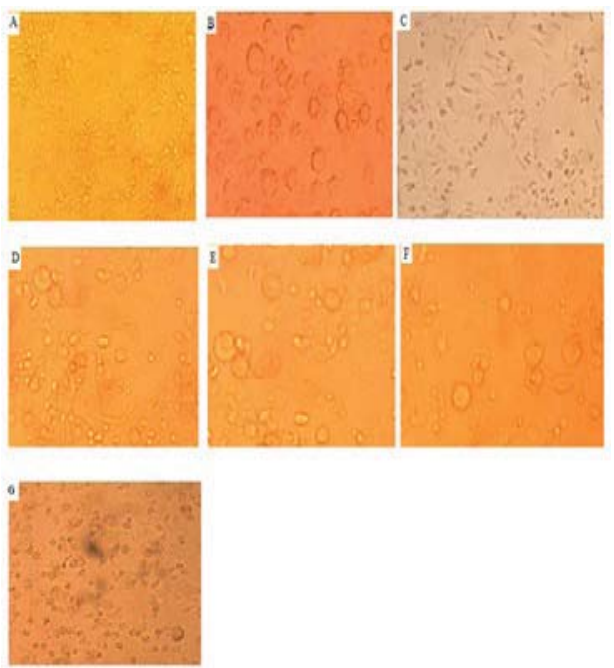

Figure 2: Morphological changes of (A) control untreated PC3 cells and treated PC3 cells for 24 h with IC50 concentration of (B) SV, (C) BV, (D) bv-PLA2, (E) sv-PLA2, (F) MEL and (G) DOX using inverted microscope. 
Effect of SV, SvPLA2, BV, bvPLA2, MEL and DOX on the expression of apoptosis related genes

As shown in (Figure 3), all treatments showed a trend of up regulation of Bax and down regulation of $\mathrm{Bcl} 2$ gene expression levels. It was noticed that $24 \mathrm{~h}$ treatment with $\mathrm{IC}_{50}$ concentration of SV, svPLA2, BV, bvPLA2, MEL and DOX increased the pro-apoptotic Bax gene expression to reach approximately 3.9-fold, 3.8-fold, 4.4-fold, 3.7fold, 6.2-fold and 7.9-fold, respectively as compared to the control value. Regarding the anti-apoptotic $\mathrm{Bcl} 2$ gene expression, treatment with SV, svPLA2, BV, bvPLA2, MEL and DOX decreased its expression by $49 \%, 33 \%$, $40 \%, 13 \%, 72 \%$ and $96 \%$, respectively.

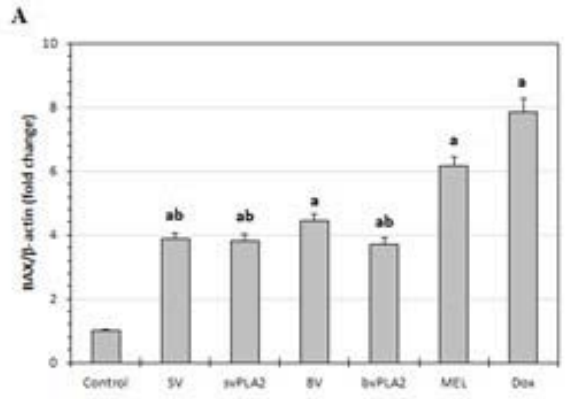

$$
\text { B }
$$

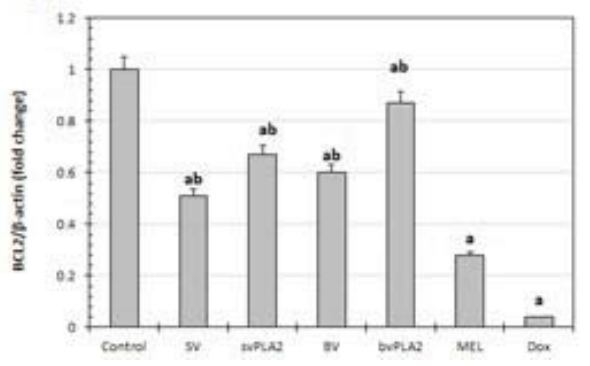

Figure 3: Effect of treatment of $\mathrm{PC} 3$ cells for $24 \mathrm{~h}$ with $\mathrm{IC}_{50}$ concentrations of SV, svPLA2, BV, bvPLA2, MEL and DOX on mRNA expression level of apoptosis related genes: (A) Bax and (B) Bcl2. Data are expressed as mean $\pm \mathrm{SD}$ of three independent experiments. a: Significantly different from control at $P<0.05$. b: Significantly different from DOX at $P<0.05$.

\section{Effect of SV, svPLA2, BV, bvPLA2 and MEL on the expression prostate cancer biomarkers (PSA and PCA3)}

As illustrated in (Figure 4), incubation of PC3 cells with $\mathrm{IC}_{50}$ concentrations of SV, svPLA2, BV, bvPLA2, MEL and DOX for $24 \mathrm{~h}$ reduced PSA gene expression levels by $57 \%, 44 \%, 87 \%, 55 \%, 10 \%$ and $98 \%$, respectively as compared to the control value. In the meantime, all treatments decreased PCA3 gene expression levels by $27 \%, 31 \%, 70 \%, 63 \%, 27 \%, 31 \%, 10 \%$ and $79 \%$, respectively as compared with the control value.

A

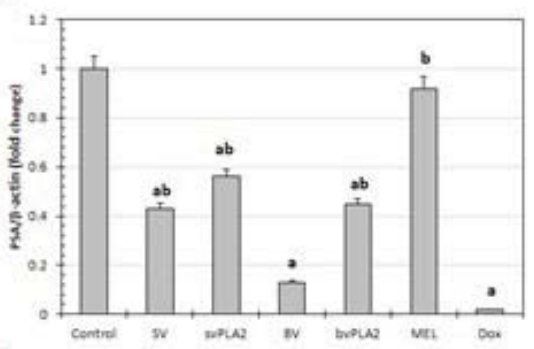

B

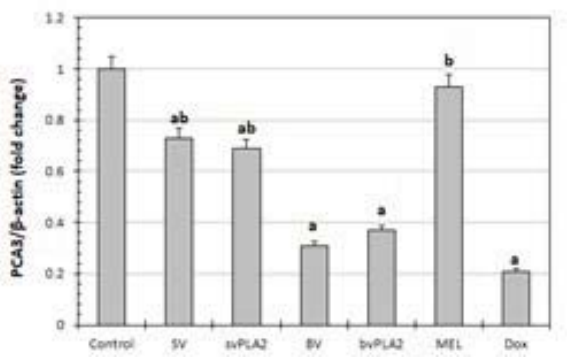

Figure 4: Effect of treatment of $\mathrm{PC} 3$ cells for $24 \mathrm{~h}$ with $\mathrm{IC}_{50}$ concentrations of SV, svPLA2, BV, bvPLA2, MEL and DOX on mRNA expression level of prostate cancer biomarkers: (A) PSA and (B) PCA3. Data are expressed as mean $\pm \mathrm{SD}$ of three independent experiments. a: Significantly different from control at $P<0.05$. b: Significantly different from DOX at $P<0.05$.

\section{Cell cycle analysis using flow cytometry}

Cell cycle analysis have demonstrated that there was an accumulation of arrested cells in the G2/M phase in PC3 cell lines after treatment with SV, svPLA2, BV, bvPLA2, MEL and DOX. In the meantime, the arrest of treated cells was accompanied by increased apoptotic population compared with that of control cells (Figures 5 and 6). The distribution of the treated cancer cells with tested compounds in different phases of the cell cycle showed that SV and svPLA2 arrested the cell cycle at $\mathrm{G} 0 / \mathrm{G} 1$ phase, which represented the DNA content in tumor cells, 24 hours post treatment. The cell cycle arrest at $\mathrm{G} 0 / \mathrm{G} 1$ phase prevent the initiation of DNA synthesis and consequently replication of tumor cells and this was indicated and represented by the decreased percentages of $\mathrm{S}$ phase in treated cancer cells compared to their controls. BV, bvPLA2 and MEL arrested cell cycle at G2/M phase which represented DNA damage that can be repaired so cells failed to enter mitosis (Figure 7). 


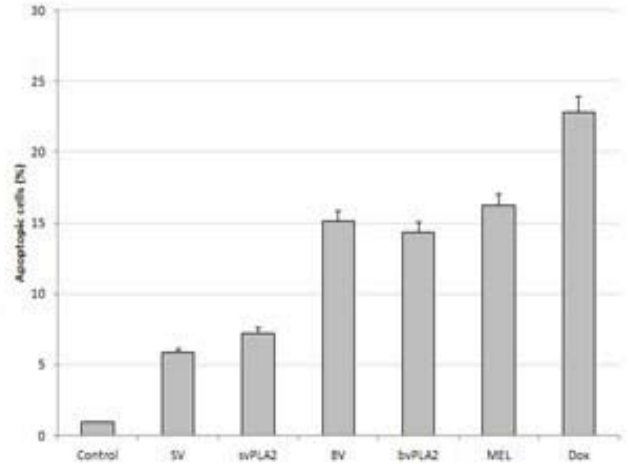

Figure 5: Evaluation of apoptotic profile of human prostate cancer cell line (PC3) post treatment with test products by flowcytometry.

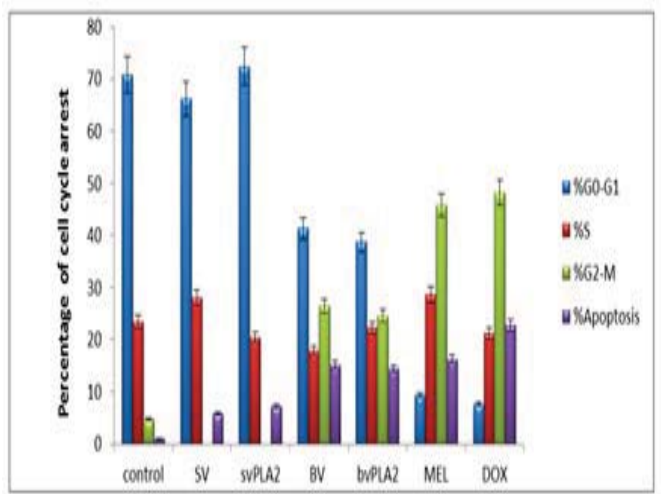

Figure 6: The percent of cell arrest at each of the cell cycle phases of PC3 cells post treatment with test products.
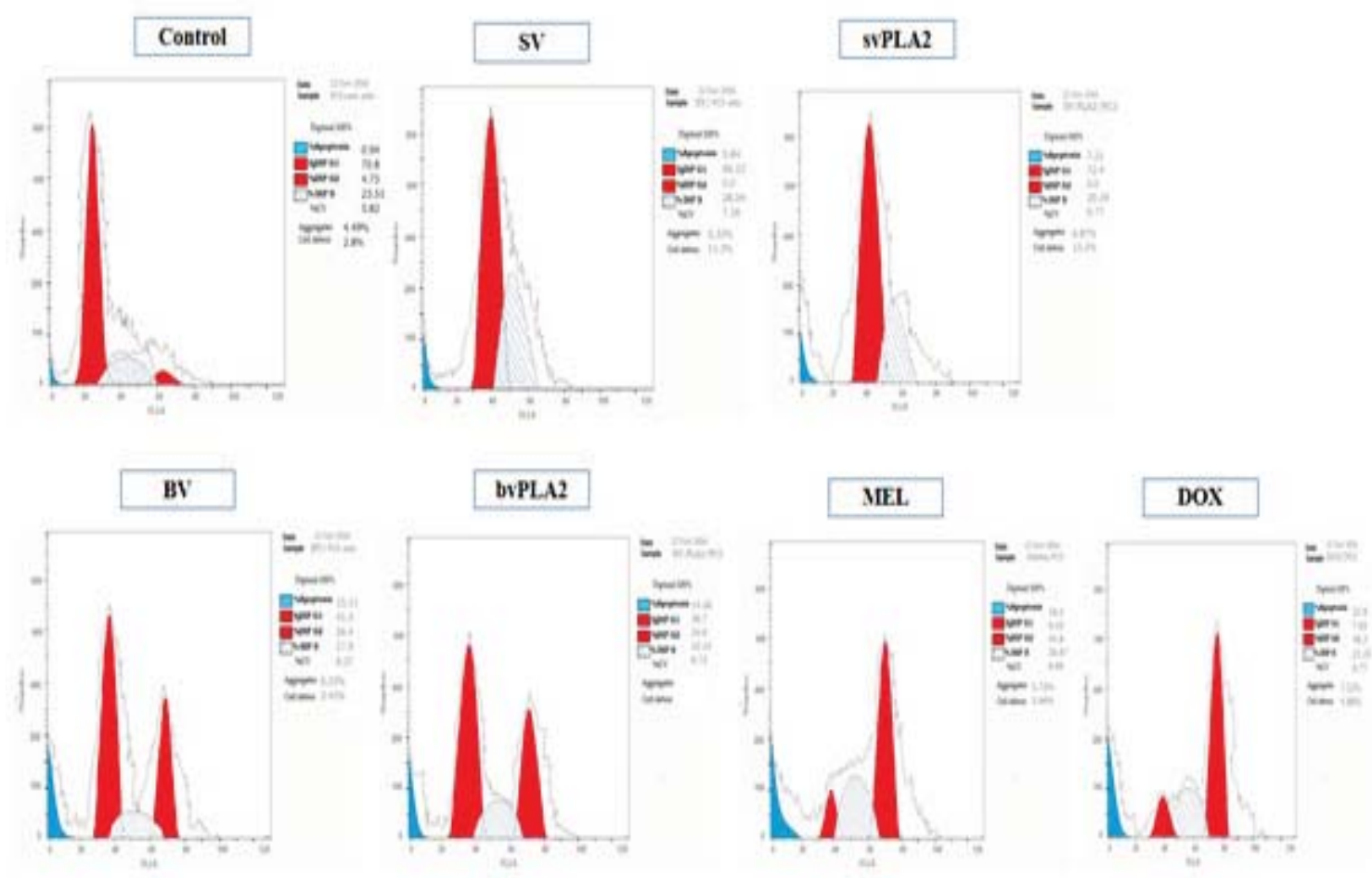

Figure 7: Effects of crude venoms and their components on cell cycle of PC3 cancer cells, post $24 \mathrm{~h}$ treatment. Flowcytometric analysis used to illustrate the distribution of $\mathrm{G} 0 / \mathrm{G} 1, \mathrm{~S}$ and $\mathrm{G} 2 / \mathrm{M}$ phases. 


\section{DISCUSSION}

Natural compounds are one of the attractive options for treatment of prostate cancer due to the prevalence of this type of cancer in elderly patients and the long latency between pre-malignant lesions and clinically evident cancer ${ }^{[18]}$. Although, snake and bee venoms and their components were reported to have potential cytotoxic effects on various types of cancer cells ${ }^{[16,19]}$, there is no information on their cytotoxicity as crude venoms compared with their major components. Accordingly, the aim of the present study was to evaluate the effect of crude $\mathrm{SV}, \mathrm{BV}$ and their major components (svPLA2, bvPLA2 and MEL) on prostate cancer cell line PC3 and to clarify the mechanisms that could be implicated in these effects.

In the present study, MTT assay showed that treatment with SV and BV and their major components (svPLA2, bvPLA2 and MEL) resulted in cellular morphological changes and significant cytotoxic effects in the prostate cancer cell lines PC3. Interestingly, our data showed that the viability of $\mathrm{PC} 3$ cells was decreased with increase of SV, BV, svPLA2, bvPLA2 and MEL concentrations in a dose dependent manner. Furthermore, our results indicate that the svPLA2 gives much lower cytotoxic effect than the crude SV in PC3 cells in the highest tested concentration of $100 \mu \mathrm{g} / \mathrm{ml}$. On the hand, the major components of BV (bvPLA2 and MEL) showed more potent efficacy on PC3 cells than the crude BV.

Our results are in accordance with previous studies which reported that SV can inhibit human prostate cancer cell growth ${ }^{[19,20]}$. Interestingly, it has been suggested that cystatin isolated from SV is a potent anti-metastatic agent that contribute to the inhibition of tumor invasion ${ }^{[21]}$. In addition, it is well documented that venoms of snakes belonging to the genera Naja contain cytotoxins that can readily penetrate into cancer cells and markedly accumulate in lysosomes causing lysosomal leakage and plasma membrane injury ${ }^{[22]}$. svPLA2s are low molecular weight enzymes that have different isoforms depending on their geographical source and species of snakes ${ }^{[23]}$. svPLA2 displays cytotoxic effects against various tumor cell lines ${ }^{[16]}$. It was previously reported that svPLA2s inhibit adhesion and migration of tumor cells ${ }^{[2,25]}$.

Our recorded data is supported by previous studies which demonstrated that BV, bvPLA2 and MEL inhibit cell proliferation in prostate cancer cells in a concentration and time-dependent manner ${ }^{[9,11,26]}$. MEL is the main active pharmacological component of BV that disturbs the integrity of membrane phospholipid bilayers by pore formation together with the leakage of atomic ions and molecules and the enhancement of permeability that eventually leads to cell lysis ${ }^{[27]}$. bvPLA2 enzymes can influence cytotoxicity of tumor cells by various mechanisms including hydrolysis and digestion of cell membrane components and disruption of the lipid bilayers integrity ${ }^{[28]}$.

Apoptosis is the process of programmed cell death that plays important roles in anti-cancer effects in various types of cancer ${ }^{[29]}$. Apoptosis occurs via two main pathways, the extrinsic and the intrinsic pathway ${ }^{[30]}$. Both pathways lead to the activation of caspases, which induce cell death ${ }^{[31]}$. The regulation of apoptotic intrinsic pathway occurs through members of the Bcl 2 family proteins that can either be pro-apoptotic or anti-apoptotic ${ }^{[32]}$. Bcl2 is an anti-apoptotic protein that prevents cell death and apoptosis whereas Bax is a pro-apoptotic protein that stimulates apoptosis ${ }^{[33]}$. $\mathrm{Bcl} 2$ blocks while Bax induces the release of apoptogenic factors, which in turn stimulate initiator caspases leading to activation of the executioner caspase- $3^{[32]}$. Herein, we showed that SV, svPLA2, BV, bvPLA2 and MEL suppressed the mRNA expression of the anti-apoptotic protein $\mathrm{Bc1} 2$, while increased the mRNA expression of the pro-apoptotic protein Bax. Thus, SV, BV and their components may induce an alteration of the expression of apoptosis regulatory proteins to provide an advantageous circumstance for the cancer cells to reach death status. These data are in harmony with a study reporting that crude cobra SV could aid in suppressing human breast and liver carcinoma progression via increasing the expression of Bax and decreasing the expression of $\mathrm{Bcl}^{[34]}$.In addition, svPLA2 showed their antitumor effect upon variety of tumor cells via induction of apoptosis ${ }^{[35]}$. Similarly, $\mathrm{BV}$, bvPLA2 and MEL are reported to induce apoptosis through a decrease in $\mathrm{Bcl} 2$ and an increase in $\mathrm{Bax}$ expression $^{[34,36-38]}$.

Screening using PSA is characterized by low specificity for prostate cancer ${ }^{[3]}$. PSA levels may be elevated in benign conditions such as benign prostatic hyperplasia or prostatitis $^{[39]}$. On the other hand, PCA3 is a genetic marker with high specificity for prostate cancer because it is typically overexpressed by cancer cells ${ }^{[39,40]}$. The data of the present study showed that SV, svPLA2, BV, bvPLA2, MEL reduced PSA and PCA3 gene expression. To our knowledge the current study is the first to investigate the possibility of using the tested venoms or their components as anticancer agents for prostate cancer through decreasing the overexpressed prostate tumor marker genes PSA and PCA3.

Cell cycle is a pathway that enhances cell death post exposure to toxins and determines the mechanism by which these pathways are regulated, thus cell cycle arrest is targeted as an intervention against cancer ${ }^{[41]}$. In our study, the cell cycle analysis showed that SV and svPLA2 arrested the cell cycle at G0/G1 phase compared to control cells, 24 hours post treatment. The increased number of cells in G0/G1 phase point out to the greater incidence of apoptotic cells post treatment and prevention of the initiation of DNA synthesis and consequently replication of tumor cells ${ }^{[42]}$. Previous studies showed that SV arrested the cell cycle at G0/G1 phase in colon and prostate cancer cell lines ${ }^{[37]}$ and in breast and liver cell lines ${ }^{[34]}$. On the other hand, BV, bvPLA2 and MEL arrested cell cycle at $\mathrm{G} 2 / \mathrm{M}$ phase. In line with our results, BV and MEL were shown to arrest the cell cycle at G2/M phase in breast and liver cell lines ${ }^{[34]}$. 
In conclusion, our work demonstrated that $\mathrm{SV}, \mathrm{BV}$ and their major components (svPLA2, bvPLA2, MEL) inhibit prostate cancer possibly via triggering apoptosis and cell cycle arrest. Future studies will help estimate the potential of SV, BV and their major components as anticancer agents for the prevention of human prostate cancer.

\section{Funding}

This research received no specific grant from any funding agency in the public or commercial.

\section{ACKNOWLEDGEMENTS}

None.

\section{CONFLICT OF INTEREST}

The authors declare no conflict of interest.

\section{REFERENCES}

1. B.W. Stewart, C.P. Wild, New International Agency for Research on Cancer, Int. Rev. Red Cross. 12 (1972) 527-527. doi:10.1017/ s0020860400079146.

2. R. Baskar, K.A. Lee, R. Yeo, K.-W. Yeoh, Cancer and Radiation Therapy: Current Advances and Future Directions, Int. J. Med. Sci. 9 (2012) 193199. doi:10.7150/ijms.3635.

3. K.L. Greene, P.C. Albertsen, R.J. Babaian, H.B. Carter, P.H. Gann, M. Han, D.A. Kuban, A.O Sartor, J.L. Stanford, A. Zietman, P. Carroll, Prostate Specific Antigen Best Practice Statement: 2009 Update, J. Urol. 182 (2009) 2232-2241. doi:10.1016/j.juro.2009.07.093.

4. R. Gerl, Apoptosis in the development and treatment of cancer, Carcinogenesis. 26 (2004) 263-270. doi:10.1093/carcin/bgh283.

5. A. Arita, D.C. McFarland, J.H. Myklebust, S Parekh, B. Petersen, J. Gabrilove, J.D. Brody, Signaling pathways in lymphoma: pathogenesis and therapeutic targets, Futur. Oncol. 9 (2013) 1549-1571. doi:10.2217/fon.13.113.

6. A. Ashkenazi, Directing cancer cells to selfdestruct with pro-apoptotic receptor agonists, Nat. Rev. Drug Discov. 7 (2008) 1001-1012. doi: $10.1038 / \mathrm{nrd} 2637$

7. W.R. Lariviere, R. Melzack, The bee venom test: A new tonic-pain test, Pain. 66 (1996) 271-277. doi:10.1016/0304-3959(96)03075-8.

8. D.J. Son, M.H. Park, S.J. Chae, S.O. Moon, J.W. Lee, H.S. Song, D.C. Moon, S.S. Kang, Y.E. Kwon, J.T. Hong, Inhibitory effect of snake venom toxin from Vipera lebetina turanica on hormonerefractory human prostate cancer cell growth: Induction of apoptosis through inactivation of nuclear factor $\kappa \mathrm{B}$, Mol. Cancer Ther. 6 (2007) 675-683. doi:10.1158/1535-7163.MCT-06-0328.

9. M.H. Park, M.S. Choi, D.H. Kwak, K.W. Oh, D.Y. Yoon, S.B. Han, H.S. Song, M.J. Song, J.T. Hong, Anti-cancer effect of bee venomin prostate cancer cells through activation of caspase pathway via inactivation of NF- $\kappa B$, Prostate. 71 (2011) 801812. doi:10.1002/pros. 21296.

10. M. Alizadehnohi, M. Nabiuni, Z. Nazari, Z. Safaeinejad, S. Irian, The synergistic cytotoxic effect of cisplatin and honey bee venom on human ovarian cancer cell line A2780cp., J. Venom Res. (2012).

11. S. Liu, M. Yu, Y. He, L. Xiao, F. Wang, C. Song, S. Sun, C. Ling, Z. Xu, Melittin prevents liver cancer cell metastasis through inhibition of the Rac1-dependent pathway, Hepatology. 47 (2008) 1964-1973. doi:10.1002/hep.22240.

12. G. Gajski, V. Garaj-Vrhovac, Melittin: A lytic peptide with anticancer properties, Environ. Toxicol. Pharmacol. 36 (2013) 697-705. doi:10.1016/j.etap.2013.06.009.

13. J.H. Park, Y.J. Jeong, K.K. Park, H.J. Cho, I.K. Chung, K.S. Min, M. Kim, K.G. Lee, J.H. Yeo, K.K. Park, Y.C. Chang, Melittin suppresses PMAinduced tumor cell invasion by inhibiting NF- $\mathrm{NB}$ and AP-1-dependent MMP-9 expression, Mol. Cells. 29 (2010) 209-215. doi:10.1007/s10059010-0028-9.

14. L.A. Calderon, J.C. Sobrinho, K.D. Zaqueo, A.A. de Moura, A.N. Grabner, M. V. Mazzi, S. Marcussi, A. Nomizo, C.F.C. Fernandes, J.P. Zuliani, B.M.A. Carvalho, S.L. da Silva, R.G. Stábeli, A.M. Soares, Antitumoral Activity of Snake Venom Proteins: New Trends in Cancer Therapy, Biomed Res. Int. 2014 (2014) 1-19. doi:10.1155/2014/203639.

15. F.J. Vonk, K. Jackson, R. Doley, F. Madaras, P.J. Mirtschin, N. Vidal, Snake venom: From fieldwork to the clinic: Recent insights into snake biology, together with new technology allowing highthroughput screening of venom, bring new hope for drug discovery, BioEssays. 33 (2011) 269-279. doi:10.1002/bies.201000117.

16. A.R. Rao, H.G. Motiwala, O.M.A. Karim, The discovery of prostate-specific antigen, BJU Int. 101 (2008) 5-10. doi:10.1111/j.1464410X.2007.07138.x.

17. K.J. Livak, T.D. Schmittgen, Analysis of relative gene expression data using real-time quantitative PCR and, Methods. 25 (2001) 402-408. doi:10.1006/meth.2001.1262. 
18. J.J. Johnson, D.N. Syed, C.R. Heren, Y. Suh, V.M. Adhami, H. Mukhtar, Carnosol, a dietary diterpene, displays growth inhibitory effects in human prostate cancer PC3 cells leading to G2phase cell cycle arrest and targets the 5'-AMPactivated protein kinase (AMPK) pathway, Pharm. Res. 25 (2008) 2125-2134. doi:10.1007/s11095008-9552-0.

19. D.J. Son, J.W. Lee, Y.H. Lee, H.S. Song, C.K. Lee, J.T. Hong, Therapeutic application of anti-arthritis, pain-releasing, and anti-cancer effects of bee venom and its constituent compounds, Pharmacol. Ther. 115 (2007) 246-270. doi:10.1016/j. pharmthera.2007.04.004.

20. G. Badr, M.K. Al-Sadoon, D.M. Rabah, D. Sayed, Snake (Walterinnesia aegyptia) venom-loaded silica nanoparticles induce apoptosis and growth arrest in human prostate cancer cells, Apoptosis. 18 (2013) 300-314. doi:10.1007/s10495-012-0787-1.

21. N. Tang, Q. Xie, X. Wang, X. Li, Y. Chen, X. Lin, J. Lin, Inhibition of invasion and metastasis of MHCC97H cells by expression of snake venom cystatin through reduction of proteinases activity and Epithelial-Mesenchymal Transition, Arch. Pharm. Res. 34 (2011) 781-789. doi:10.1007/ s12272-011-0512-6.

22. A. V. Feofanov, G. V. Sharonov, M.A. Dubinnyi, M. V. Astapova, I.A. Kudelina, P. V. Dubovskii, D.I. Rodionov, Y.N. Utkin, A.S. Arseniev, Comparative study of structure and activity of cytotoxins from venom of the cobras naja oxiana, naja kaouthia, and naja haje, Biochem. 69 (2004) 1148-1157. doi:10.1023/B:BIRY.0000046890.46901.7e.

23. G.A.C. Barros, A. V. Pereira, L.C. Barros, A. Lourenço, S.A. Calvi, L.D. Santos, B. Barraviera, R.S. Ferreira, In vitro activity of phospholipase A2 and of peptides from Crotalus durissus terrificus venom against amastigote and promastigote forms of Leishmania (L.) infantum chagasi, J. Venom. Anim. Toxins Incl. Trop. Dis. 21 (2015). doi:10.1186/s40409-015-0049-0.

24. R. Zouari-Kessentini, J. Luis, A. Karray, O. Kallech-Ziri, N. Srairi-Abid, A. Bazaa, E. Loret, S. Bezzine, M. El Ayeb, N. Marrakchi, Two purified and characterized phospholipases A2 from Cerastes cerastes venom, that inhibit cancerous cell adhesion and migration, Toxicon. 53 (2009) 444-453. doi:10.1016/j.toxicon.2009.01.003.

25. A. Bazaa, J. Luis, N. Srairi-Abid, O. KallechZiri, R. Kessentini-Zouari, C. Defilles, J.C. Lissitzky, M. El Ayeb, N. Marrakchi, MVL-PLA2, a phospholipase A2 from Macrovipera lebetina transmediterranea venom, inhibits tumor cells adhesion and migration, Matrix Biol. (2009). doi:10.1016/j.matbio.2009.03.007.

26. K.E. Choi, C.J. Hwang, S.M. Gu, M.H. Park, J.H. Kim, J.H. Park, Y.J. Ahn, J.Y. Kim, M.J. Song, H.S. Song, S.B. Han, J.T. Hong, Cancer cell growth inhibitory effect of bee venom via increase of death receptor 3 expression and inactivation of NF-kappa B in NSCLC cells, Toxins (Basel). 6 (2014) 2210-2228. doi:10.3390/toxins6082210.

27. E. Jamasbi, A. Mularski, F. Separovic, Model Membrane and Cell Studies of Antimicrobial Activity of Melittin Analogues, Curr. Top. Med. Chem. 16 (2015) 40-45. doi:10.2174/156802661 5666150703115919 .

28. I. Kudo, M. Murakami, Phospholipase A2 enzymes, Prostaglandins Other Lipid Mediat. 68-69 (2002) 3-58. doi:10.1016/S0090-6980(02)00020-5.

29. F. Kruiswijk, C.F. Labuschagne, K.H. Vousden, P53 in survival, death and metabolic health: A lifeguard with a licence to kill, Nat. Rev. Mol. Cell Biol. 16 (2015) 393-405. doi:10.1038/nrm4007.

30. X. Zhang, P. Yue, B.D.G. Page, T. Li, W. Zhao, A.T. Namanja, D. Paladino, J. Zhao, Y. Chen, P.T. Gunning, J. Turkson, Orally bioavailable smallmolecule inhibitor of transcription factor Stat3 regresses human breast and lung cancer xenografts, Proc. Natl. Acad. Sci. U. S. A. 109 (2012) 96239628. doi:10.1073/pnas.1121606109.

31. A.M. Hunter, E.C. LaCasse, R.G. Korneluk, The inhibitors of apoptosis (IAPs) as cancer targets, Apoptosis. 12 (2007) 1543-1568. doi:10.1007/ s10495-007-0087-3.

32. J.M. Adams, S. Cory, The Bcl-2 apoptotic switch in cancer development and therapy, Oncogene. 26 (2007) 1324-1337. doi:10.1038/sj.onc.1210220.

33. T. Lindsten, W.X. Zong, C.B. Thompson, Defining the role of the Bcl-2 family of proteins in the nervous system, Neuroscientist. 11 (2005) 10-15. doi: $10.1177 / 1073858404269267$.

34. F.Z. El Sharkawi, S.S. Saleh, A.F.M. El Sayed, Potential Anti Cancer Activity of Snake Venom, Bee Venom and Their Components in Liver and Breast Carcinoma, Int. J. Pharm. Sci. Res. 6 (2015) 0-6. doi:10.13040/IJPSR.0975-8232.6(8).3224-35.

35. M. Samel, H. Vija, I. Kurvet, K. Künnis-Beres, K. Trummal, J. Subbi, A. Kahru, J. Siigur, Interactions of PLA2-s from Vipera lebetina, Vipera berus berus and Naja naja oxiana venom with platelets, bacterial and cancer cells, Toxins (Basel). 5 (2013) 203-223. doi:10.3390/toxins5020203. 
36. D.J. Son, J.W. Lee, Y.H. Lee, H.S. Song, C.K. Lee, J.T. Hong, Therapeutic application of anti-arthritis, pain-releasing, and anti-cancer effects of bee venom and its constituent compounds, Pharmacol. Ther. 115 (2007) 246-270. doi:10.1016/j. pharmthera.2007.04.004.

37. H. Akef, N. Kotb, D. Abo-Elmatty, S. Salem, Antiproliferative Effects of Androctonus amoreuxi Scorpion and Cerastes cerastes Snake Venoms on Human Prostate Cancer Cells, J. Cancer Prev. 22 (2017) 40-46. doi:10.15430/jcp.2017.22.1.40.

38. M. Jo, M.H. Park, P.S. Kollipara, B.J. An, H.S. Song, S.B. Han, J.H. Kim, M.J. Song, J.T. Hong, Anti-cancer effect of bee venom toxin and melittin in ovarian cancer cells through induction of death receptors and inhibition of JAK2/STAT3 pathway, Toxicol. Appl. Pharmacol. 258 (2012) 72-81. doi:10.1016/j.taap.2011.10.009.
39. A.R. Rao, H.G. Motiwala, O.M.A. Karim, The discovery of prostate-specific antigen, BJU Int. 101 (2008) 5-10. doi:10.1111/j.1464410X.2007.07138.x.

40. J.A. Schalken, D. Hessels, G. Verhaegh, New targets for therapy in prostate cancer: Differential display code 3 (DD3PCA3), a highly prostate cancer-specific gene, Urology. 62 (2003) 34-43. doi:10.1016/S0090-4295(03)00759-3.

41. J.A. Pietenpol, Z.A. Stewart, Cell cycle checkpoint signaling: Cell cycle arrest versus apoptosis, Toxicology. 181-182 (2002) 475-481. doi:10.1016/S0300-483X(02)00460-2.

42. S.H. Van Rijt, I. Romero-Canelón, Y. Fu, S.D. Shnyder, P.J. Sadler, Potent organometallic osmium compounds induce mitochondria-mediated apoptosis and S-phase cell cycle arrest in A549 non-small cell lung cancer cells, Metallomics. 6 (2014) 1014-1022. doi:10.1039/c4mt00034j. 